\title{
Leopard Panthera pardus density and survival in an ecosystem with depressed abundance of prey and dominant competitors
}

\author{
Milan A. Vinks, Scott Creel, Elias Rosenblatt, Matthen S. Becker \\ Paul Schuette, Ben Goodheart, Carolyn Sanguinetti \\ Kambirir Banda, Chive Chifunte and Chuma Simukonda
}

\begin{abstract}
The leopard Panthera pardus is in range-wide decline, and many populations are highly threatened. Prey depletion is a major cause of global carnivore declines, but the response of leopard survival and density to this threat is unclear: by reducing the density of a dominant competitor (the lion Panthera leo) prey depletion could create both costs and benefits for subordinate competitors. We used capturerecapture models fitted to data from a 7-year camera-trap study in Kafue National Park, Zambia, to obtain baseline estimates of leopard population density and sex-specific apparent survival rates. Kafue is affected by prey depletion, and densities of large herbivores preferred by lions have declined more than the densities of smaller herbivores preferred by leopards. Lion density is consequently low. Estimates of leopard density were comparable to ecosystems with more intensive protection and favourable prey densities. However, our study site is located in an area with good ecological conditions and high levels of protection relative to other portions of the ecosystem, so extrapolating our estimates across the Park or into adjacent Game Management Areas would not be valid. Our results show that leopard density and survival within north-central Kafue remain good despite prey depletion, perhaps because (1) prey depletion has had weaker effects on preferred
\end{abstract}

MILAN A. VINKs* (Corresponding author, (1) orcid.org/0000-0002-9291-8884), Scott Creel ${ }^{*} \dagger$, Matthew S. Becker ${ }^{*}$ and Ben GoodhearT* Department of Ecology, Montana State University, Bozeman, USA

E-mail milan.vinks@gmail.com

Elias RosenblatT Rubenstein School of Environment and Natural Resources, University of Vermont, Aiken Center, Burlington, USA

Paul Schuette U.S. Fish \& Wildlife Service, Marine Mammals Management, Anchorage, USA

Carolyn Sanguinetti and Kambwiri Banda Zambian Carnivore Programme, Mfuwe, Zambia

CuIve Chifunte $\ddagger$ Institut för Vilt, Fisk Och Miljö, Sveriges Lantbruksuniversitet, Umea, Sweden

Chuma Simukonda Zambian Department of National Parks and Wildlife, Lusaka, Zambia

*Also at: Zambian Carnivore Programme, Mfuwe, Zambia

$\dagger$ Also at: Institut för Vilt, Fisk Och Miljö, Sveriges Lantbruksuniversitet, Umea, Sweden

¥Also at: Zambian Department of National Parks and Wildlife, Lusaka, Zambia

Received 21 October 2020. Accepted 4 February 2021

First published online 25 August 2021. leopard prey compared to larger prey preferred by lions, and (2) the density of dominant competitors is consequently low. Our results show that the effects of prey depletion can be more complex than uniform decline of all large carnivore species, and warrant further investigation.

Keywords Kafue National Park, leopard, Panthera pardus, population density, prey density, prey depletion, survival, Zambia

\section{Introduction}

The leopard Panthera pardus is a generalist predator that 1 is consistently found outside protected areas (Athreya et al., 2011; Swanepoel et al., 2013; Odden et al., 2014). However, the ability of leopards to occupy landscapes affected by humans does not exempt them from threats associated with increasing anthropogenic pressure (Jacobson et al., 2016), and negative anthropogenic effects on leopard populations in sub-Saharan Africa have been reported (Balme et al., 2010; Henschel et al., 2011; Rosenblatt et al., 2016; Stein et al., 2020; Naude et al., 2020). The strength of such anthropogenic effects is not well known, largely because it is difficult to obtain precise data on population density and survival (Durant et al., 2007). Like other African carnivores, the leopard is in decline, and many subspecies and regional populations are highly threatened (Ripple et al., 2014; Jacobson et al., 2016). The species' broad geographical distribution, generalist ecology, and cryptic nature has led to a misconception that this might not be the case (Jacobson et al., 2016; Stein et al., 2020), and much research on leopards has consequently focused on issues other than conservation (Balme et al., 2014).

The causes of leopard population decline are habitat loss and fragmentation, conflict with people, unsustainable trophy hunting, poaching for body parts, indiscriminate killing, and prey depletion (Athreya et al., 2011; Packer et al., 2011; Nijman et al., 2019; Stein et al., 2020). The latter in particular has been identified as a major issue for leopards in Central Africa (Henschel et al., 2011), but little work has evaluated leopard population density and survival in other African protected areas affected by prey depletion. 


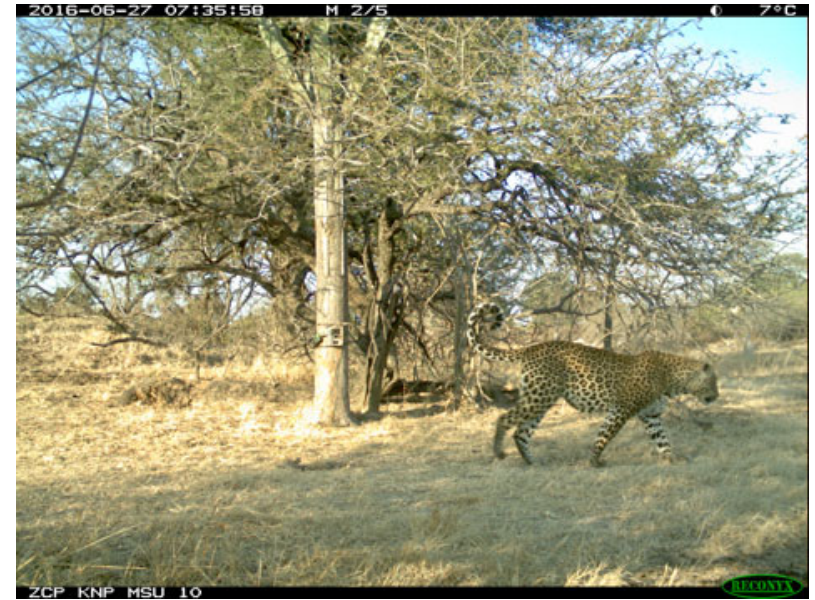

Plate 1 A camera trap captures a male leopard Panthera pardus travelling in the early morning in Kafue National Park, Zambia.

Prey depletion is apparent in many ecosystems affected by illegal offtake (Bolger et al., 2008; Fa \& Brown, 2009; Western et al., 2009; Ripple et al., 2015). Because this type of offtake is unregulated, it is often unsustainable, driving extensive wildlife population declines and disproportionately affecting larger-bodied herbivores (Wilkie \& Carpenter, 1999; Fa et al., 2000; Creel et al., 2018; Vinks et al., 2020). Herbivore declines, in turn, are widely thought to be a strong driver of carnivore declines in sub-Saharan Africa (Midlane et al., 2014; Rosenblatt et al., 2016, 2019; Creel et al., 2018; Vinks et al., 2021).

Western Zambia's Greater Kafue Ecosystem, comprising Kafue National Park and surrounding Game Management Areas, has been identified as a potential leopard stronghold, on the basis of historical data (Purchase et al., 2007). Little is known about the current status of leopards in the Greater Kafue Ecosystem, although this system now faces extensive anthropogenic pressures from encroachment (Watson et al., 2014) and illegal offtake (Overton et al., 2017), with effects on the large herbivore and carnivore guilds (Creel et al., 2018; Vinks et al., 2020; Vinks et al., 2021). Specifically, the longterm decline of large-bodied prey species has led to prey base homogenization, niche compression, and increased niche overlap within the large carnivore guild, including of leopards and lions Panthera leo (Creel et al., 2018). The consequences of these changes for the conservation of subordinate competitors such as leopards cannot be evaluated without data on density and demography. More broadly, reliable and precise estimates of population size and vital rates (survival and reproductive parameters) are needed to design and evaluate actions for the conservation and management of leopard populations, especially in protected areas facing anthropogenic pressures suspected of causing declines (Jacobson et al., 2016; Rosenblatt et al., 2016).

Individual leopards are identifiable through their unique markings (Plate 1; Miththapala et al., 1989), facilitating effective monitoring with passive camera trap arrays (Balme et al., 2009a,b; Goldberg et al., 2015; Rosenblatt et al., 2016; Balme et al., 2019). Camera-trap data have been used to estimate population densities in many parts of the species' range (Balme et al., 2019). However, substantial gaps still exist in our understanding of the drivers of leopard population dynamics (Balme et al., 2014; Jacobson et al., 2016; Stein et al., 2020), particularly with regard to the consequences of prey depletion. Although the loss of prey is generally expected to cause carnivore declines, the densities of dominant competitors (especially lions) are more strongly correlated with prey density than the densities of subordinate competitors (Van Orsdol et al., 1985; Laurenson, 1995; Creel \& Creel, 2002). Because a decrease in prey density is likely to reduce the density of dominant competitors, its net effect on the survival and population density of leopards is difficult to predict. Prediction of this effect is further complicated by studies suggesting that competitive limitation of leopards by dominant competitors is weaker (Rosenblatt et al., 2016; Balme et al., 2017; Miller et al., 2018) than for other competitive subordinates such as the African wild dog Lycaon pictus (Creel \& Creel, 2002; Swanson et al., 2014).

Here, we use data from a 7-year camera-trap study of leopards in north-central Kafue National Park to fit capturerecapture models to provide unbiased estimates of population density and sex-specific apparent survival rates, accounting for imperfect detection. By comparing our estimates of density and apparent survival to data from other leopard populations, we evaluate the consequences of prey depletion in the Greater Kafue Ecosystem.

\section{Study area}

We established a camera-trap grid in north-central Kafue National Park west of the Kafue river, and along the Lufupa river (Fig. 1). Kafue lies in western Zambia, and is the country's largest protected area at $22,319 \mathrm{~km}^{2}$. Kafue and the surrounding Game Management Areas comprise the $66,000 \mathrm{~km}^{2}$ Greater Kafue Ecosystem, which is dominated by miombo woodland (Brachystegia and Julbernardia spp.) with a mosaic of savannah grassland, riverine woodland, mixed acacia woodland, termitaria woodland, and seasonally inundated grasslands. The region experiences a rainy season with extensive flooding during December-April and a dry season during May-November. Carnivore prey are depleted in Kafue, and densities of larger-bodied herbivores are depressed relative to smaller species. To evaluate the impacts of both prey depletion and interspecific competition with lions, we focused on the central portion of Kafue, for which there are well-described lion and herbivore densities and dynamics from long-term studies (Vinks et al., 2020, 2021). 


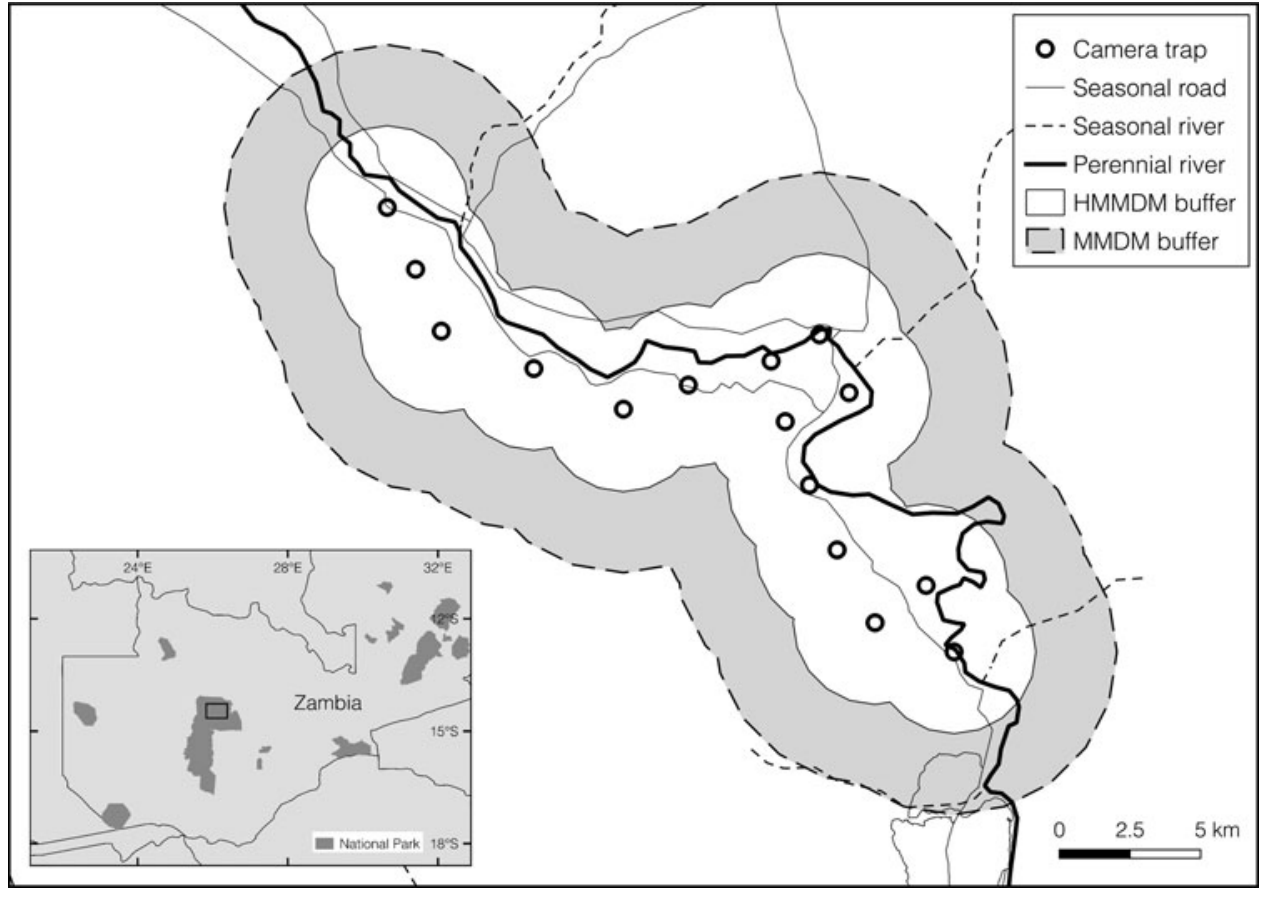

FIG. 1 Study area in Kafue National Park, Zambia. Buffer zones identify the areas effectively sampled based on the mean maximum distance moved (MMDM; $538 \mathrm{~km}^{2}$ ) and half of the mean maximum distance moved (HMMDM; $228 \mathrm{~km}^{2}$ ).

\section{Methods}

\section{Study design}

We used a grid of camera traps to photograph individual leopards and used a combination of open and closed capture-recapture models to estimate population size, population density, and sex-specific annual survival rates. Cameras were placed within a square grid that was random in its origin and orientation, following Rosenblatt et al. (2016). Grid spacing followed established procedures for large felids to meet the assumptions of closed capturerecapture models (Otis et al., 1978; Karanth \& Nichols, 1998; Balme et al., 2009a,b). We based grid cell size on the smallest home range estimate $\left(14 \mathrm{~km}^{2}\right)$ for an adult female leopard in Zambia's Luambe National Park (Ray, 2011), and spaced camera-trap sites $2.5 \mathrm{~km}$ apart (Fig. 1). This spacing ensured several sites within the home range of each individual (Karanth \& Nichols, 1998), to increase the probability of detection.

We established 15 unbaited camera-trap sites (Fig. 1), selecting sites by searching for leopard tracks within $100 \mathrm{~m}$ of each (uniformly distributed) grid point (Silver et al., 2004). If we encountered no tracks, we selected the most active game trail within $100 \mathrm{~m}$ of the point (Rosenblatt et al., 2016). Although vegetation varied between sites, we expected leopards to use all vegetation types (Balme et al., 2007).

At each site we placed two Reconyx Hyperfire PC80o cameras (Reconyx, Inc., Holmen, USA) opposite one another, to photograph both sides of passing leopards, and attached each camera to a tree at a height and angle selected to maximize the likelihood of being triggered by leopards (Rosenblatt et al., 2016). To download images, we visited sites on foot in small groups to minimize our potential effect on subsequent detections. Individuals were identified by spot patterns, and sex was determined based on genitalia and sexually dimorphic traits such as body size, head size, and the prominence of the neck dewlap (Balme et al., 2012). We did not assign ages because of the limitations of image quality and the difficulty of aging leopards accurately (Balme et al., 2012).

\section{Modelling abundance and survival}

Our sampling was restricted to 6 months (June-November) annually, when conditions allowed for consistent monitoring across the entire study site. We deployed cameras in a random rotation across three sections within the study area (Karanth, 1995). Each section consisted of 5 sites and was sampled for 20 days on two occasions (40 days total) in each 6-month period. To estimate survival rates, we created encounter histories for each individual by pooling detections across sections for each 20-day period (see below). To estimate abundance, we divided each 20 -day primary occasion into two 10-day secondary occasions (see below). To avoid double-counting individual leopards, we created encounter histories using only right-side photographs (Rosenblatt et al., 2016).

Our study was designed to estimate population size, annual survival, detection and redetection probabilities, and rates of temporary emigration, using an extended robust design model (Pollock, 1982; Kendall et al., 1995), which was used for data from the same sampling design in another 
Zambian leopard population (Rosenblatt et al., 2016). Because we obtained far fewer detections, this model could not be fit, and therefore we modelled annual survival and abundance using open and closed capture-recapture models, respectively.

\section{Survival}

We used 7 years (2013-2019) of detection records for 26 unique leopards and fitted Cormack-Jolly-Seber models to estimate sex-specific annual survival rates $(\varphi)$, and detection probability $(P)$, that allowed for individual heterogeneity in detection (Pledger et al., 2010). Detections were recorded for two 20-day occasions per year, so that the detection (1) or non-detection (o) of each individual in each 20 -day period yielded a 14-occasion encounter history for each individual over the 7-year study, with staggered entry. We constructed an a priori set of Cormack-Jolly-Seber models that allowed survival and detection rates to vary by sex and year, and used RMark (Laake, 2013) and MARK (White \& Burnam, 1999) to identify which of these 72 models were best-supported, using Akaike's information criteria corrected for small sample size (AICc). We then used model averaging to estimate sexspecific apparent survival, using all models with $\Delta$ AICc $<2$.

\section{Abundance}

We used annual detection histories for individual leopards and fitted Huggins closed population models to estimate the probability of initial detection, subsequent detection, and population size in each year using RMark and MARK (Huggins, 1989). We did not incorporate an effect of individual heterogeneity on detection because AICc scores provided little evidence for heterogeneity in detection from the top Cormack-Jolly-Seber survival models. To further mimic the parameterization of the detection process from the top Cormack-Jolly-Seber survival models, we constrained detection by assuming no difference between the likelihood of initial detection and subsequent detection $(P=c)$. This constraint kept our estimates of abundance consistent with our Cormack-Jolly-Seber estimates of survival, in which the probability of detection is conditional on the first detection (Mweetwa et al., 2018).

For each 6-month period we constructed a detection history of four 10-day occasions, recording whether each leopard was detected (1) or not (o) within each 10-day window. We also used the model of detection selected using AICc scores for the Cormack-Jolly-Seber models to model population size (Mweetwa et al., 2018). We focused our inferences about population density on results for 2016, because it was the only year with sufficient data to provide a precise estimate. We estimated an initial sampling area by calculating the mean maximum distance moved (MMDM; Stickel, 1954; Wilson \& Anderson, 1985) for all individuals across the

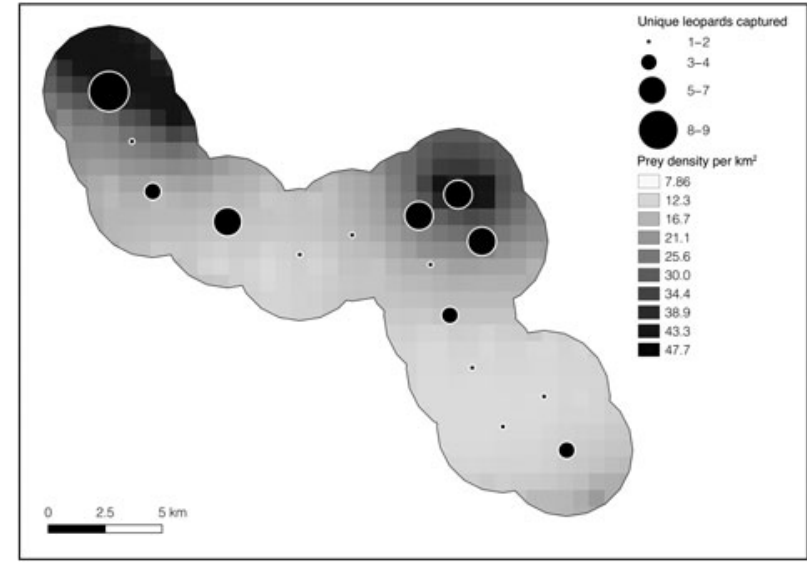

FIg. 2 Total number of leopards Panthera pardus captured at each camera-trap site in Kafue National Park (Fig. 1) overlain on the gradient of preferred leopard prey density (puku Kobus vardonii, impala Aepyceros melampus, warthog Phacochoerus africanus). Although leopards were detected at each site, the majority of individuals were detected at sites with a higher density of preferred prey.

entire study and buffered each camera-trap site by half of the mean maximum distance moved distance (HMMDM; Balme et al., 2009a,b; Gray \& Prum, 2012; Rosenblatt et al., 2016). However, there are concerns that HMMDM may overestimate density estimates by underestimating space use of individuals (Tobler \& Powell, 2013), an important consideration given our predominantly linear camera-trap configuration, relatively few cameras, and block sampling design (Tobler \& Powell, 2013). We therefore also report an alternative sampling area derived from the mean maximum distance moved (Wilson \& Anderson, 1985). We did not use alternative spatially explicit models, for reasons explained in the Discussion. Despite these limitations, a simple closed capture-recapture model yielded a relatively precise baseline estimate of leopard density for 2016. We then compared our estimate of population density to estimates from other protected areas across Africa to assess the status of leopards in this portion of Kafue National Park.

\section{Preferred leopard prey density}

We have previously identified (Creel et al., 2018) the prey species preferred by leopards in northern Kafue: puku Kobus vardonii, impala Aepyceros melampus and warthog Phacochoerus africanus. We have previously described the distribution and abundance of these prey species using distance sampling models fitted to data from a line-transect network that includes the camera-trap grid used here, sampled 15 times over the same time period as this study (Vinks et al., 2020). Here, we used these models to map the density of the prey species preferred by Kafue leopards across the sampling area for leopards (Fig. 2). Predicted prey 


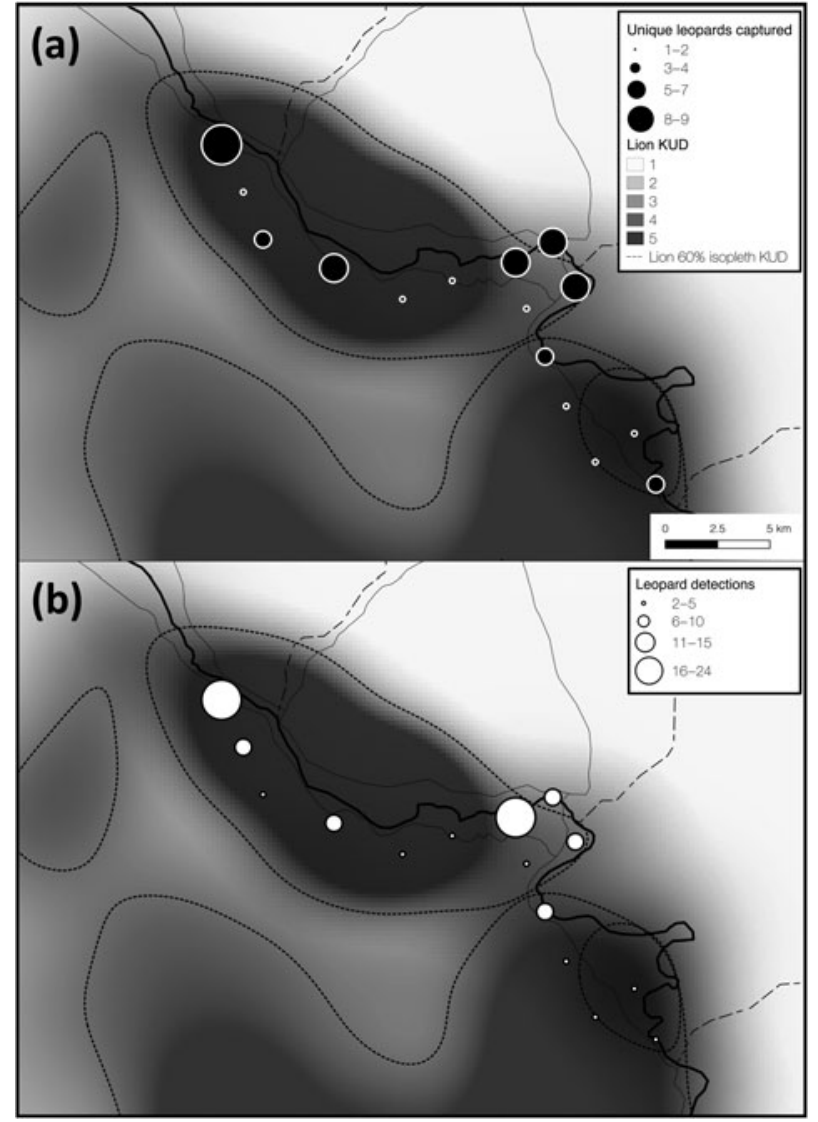

FIG. 3 Total number of (a) unique leopards captured, and (b) all leopard detections at each camera-trap site overlain on the gradient of space use (kernel utilization distribution, KUD) for two locally resident (and closely monitored) African lion Panthera leo prides (data from Vinks et al., 2021). Lion kernel utilization distribution values of 1-5 represent low-high space use and the $60 \%$ isopleth was derived from this gradient. Leopard space use appeared to overlap lion space use, suggesting that leopards are not strongly limited by interspecific competition.

densities for our camera-trap grid were then compared with leopard detections.

\section{Results}

\section{Leopard population structure}

From 4,200 camera-trap days we recorded 101 leopard detections and identified 29 individuals ( 17 females, 9 males and 3 unknown) during 2013-2019. The number of leopard detections at each site was $1-24$ (mean 6.7, median 4) and leopards were detected at all 15 sites (Figs 2 \& 3). Each site detected 1-9 (mean 3.3) individuals, with the majority of individuals at the northern-most site (Figs $2 \& 3$ ). Throughout the course of the study we detected a mean of 9 (range 7-12) leopards annually (Table 1). The sex ratio for 26 individuals incorporated in the survival analysis was 1 male:1.89 females.

\section{Survival rates and detection probabilities}

Three Cormack-Jolly-Seber models were identified as the best-supported models of leopard survival (Table 2), and these models suggested that both detection $(P)$ and apparent survival $(\varphi)$ varied by sex. However, the model-averaged estimate of apparent survival for females (0.73, 95\% CI 0.560.85) was similar to that of males (0.74, 95\% CI $0.56-0.87)$. The probability of detection was relatively low, with modelaveraged estimates of 0.35 (95\% CI $0.24-0.48)$ for females and 0.33 (95\% CI $0.22-0.47$ ) for males.

\section{Population density}

We detected 12 individual leopards in 20 total detections in 2016, nine of which (69\%) were known previous to the study. In addition, we detected one dependent cub, which we excluded from the abundance estimate. The estimated population size in 2016 was 18 (95\% CI 12-33). The HMMDM and MMDM between detections for 11 leopards recaptured at multiple sites (2013-2019) were $2.69 \mathrm{~km}$ (range: $1.2-5.7 \mathrm{~km}$ ) and 5.38 (range: $2.4-11.4 \mathrm{~km}$ ), respectively. Applying these buffers to the camera-trap locations yields a sampling area of $228 \mathrm{~km}^{2}$ and $538 \mathrm{~km}^{2}$ centred along the Lufupa river (Fig. 1). These estimates of population size and sampling area yield a density of 7.89 leopards per $100 \mathrm{~km}^{2}$ (95\% CI 6.1414.47 leopards per $100 \mathrm{~km}^{2}$ ) and 3.34 leopards per $100 \mathrm{~km}^{2}$ (95\% CI 2.23-6.13 leopards per $100 \mathrm{~km}^{2}$ ), respectively.

\section{Discussion}

Leopard population density or demography are rarely evaluated in large African protected areas of high conservation concern (Balme et al., 2014). Improving our understanding of the effects of anthropogenic pressures on leopard populations is a critical first step for leopard conservation. In the Greater Kafue Ecosystem, recent research has shown that ungulate prey density is considerably lower than expected for an ecosystem with its vegetation type and rainfall (Vinks et al., 2020), and low prey density leads to a logical expectation of low carnivore density, and, if severe, lower adult survival (Van Orsdol et al., 1985; Stander et al., 1997; Eberhardt, 2002). Moreover, reductions in density have been particularly great for large prey species that were previously preferred by lions, squeezing the entire carnivore guild into a narrow dietary niche centred on the species preferred by leopards (Creel et al., 2018). Consequently, we would expect that increased interspecific competition within the carnivore guild could exacerbate the effects of prey depletion. On the other hand, the densities of dominant competitors within this guild (lions and spotted hyenas Crocuta crocuta) correlate with the density of prey, both within and between ecosystems (Schaller, 1972; Van Orsdol et al., 1985; Hofer \& East, 1995). Thus, the direct effect 
TABLE 1 Leopard Panthera pardus camera-trap detections during 2013-2019. We considered leopards new in this study if they had not been previously documented on the study site in 2013-2019 (through either opportunistic observations or camera traps).

\begin{tabular}{lllllll}
\hline Year & Total detections & Individuals detected & Female & Male & Unknown sex & New in this study \\
\hline 2013 & 21 & 10 & 7 & 3 & 0 & 10 \\
2014 & 15 & 10 & 4 & 4 & 2 & 6 \\
2015 & 13 & 8 & 4 & 4 & 0 & 2 \\
2016 & 19 & 12 & 9 & 3 & 0 & 3 \\
2017 & 11 & 7 & 2 & 4 & 1 & 1 \\
2018 & 10 & 9 & 3 & 4 & 2 & 5 \\
2019 & 12 & 7 & 5 & 0 & 2 & 2 \\
\hline
\end{tabular}

of prey depletion on leopards could be partially offset by a decrease in the limiting effect of competition, if any exists (Rosenblatt et al., 2016; Balme et al., 2017; Miller et al., 2018).

This study provided baseline estimates of sex-specific annual survival rates and population density for leopards in north-central Kafue, and is one of few studies to provide such results for leopards in miombo woodland, which constitutes a large portion of the species' range across Zambia and Tanzania (Balme et al., 2007; Rosenblatt et al., 2016). Contrary to our predictions, density estimates were comparable to those in ecosystems with relatively greater protection, where ecological conditions (notably preferred prey abundance) remain favourable for leopards (Ray, 2011; Du Preez et al., 2014; Swanepoel et al., 2015a,b; Rosenblatt et al., 2016, 2019). Although leopard density in our study site was not precariously low, this site is located in the heart of northern Kafue, with relatively high densities of preferred leopard prey, along a major perennial river, and mostly removed from negative anthropogenic edge effects typical outside the core of the Park. Densities of preferred leopard prey are substantially reduced in other parts of the Park and adjacent Game Management Areas (Creel et al., 2018; Schuette et al., 2018; Vinks et al., 2020), and there is evidence of wire snare poaching bycatch in addition to targeted poaching in areas of the Greater Kafue Ecosystem with

TABLE 2 The best-supported Cormack-Jolly-Seber models of leopard survival, as determined by Akaike's information criteria corrected for small sample size (AICc).

\begin{tabular}{lllll}
\hline Model $^{1}$ & $K^{2}$ & $\Delta$ AICc $^{3}$ & Weight & Deviance \\
\hline$\varphi() P.()$. & 2 & 0 & 0.307 & 145.735 \\
$\varphi() P.(\sim$ sex $)$ & 3 & 1.834 & 0.123 & 145.355 \\
$\varphi(\sim \operatorname{sex}) P()$. & 3 & 1.991 & 0.114 & 145.513 \\
$\varphi() P.(.) \pi()$. & 3 & 2.214 & 0.102 & 145.735 \\
$\varphi() P.(\sim$ study year $)$ & 8 & 2.716 & 0.079 & 133.889 \\
$\varphi(\sim \operatorname{sex}) P(\sim$ sex $)$ & 4 & 3.547 & 0.052 & 144.775 \\
$\varphi() P.(\sim \operatorname{sex}) \pi()$. & 4 & 4.127 & 0.039 & 145.355 \\
\hline
\end{tabular}

${ }^{1} \varphi$, apparent survival rate; $P$, detection probability; $\pi$, mixture parameter.

${ }^{2} K$, number of parameters.

${ }^{3} \mathrm{AICc}$, difference in AICc to the best performing model. less protection (Overton et al., 2017). Thus, extrapolating our density estimate across other portions of the Park or Game Management Areas, where ecological conditions are less favourable and human pressures are known to be stronger (Watson et al., 2014; Overton et al., 2017; Schuette et al., 2018), would not be valid (Trouwborst et al., 2019).

We did not fit spatial capture-recapture models, which are widely used in conjunction with leopard camera-trap data (Du Preez et al., 2014; Goldberg et al., 2015; Balme et al., 2019; Devens et al., 2019). When the number of redetections is low, the data do not allow good estimates of spatial capture-recapture model parameters, yielding a biased and imprecise density estimate (Efford et al., 2004; Du Preez et al., 2014; Paterson et al., 2019). Instead, we used a randomized grid with a spacing tailored to leopard movements to produce a representative estimate of density for the sampled area.

As with other large carnivores, leopard density is generally expected to be positively correlated with preferred prey biomass at a system-wide scale (Stander et al., 1997; Marker \& Dickman, 2005). This logic leads to an expectation that Kafue leopard density should be low (Henschel et al., 2011; Balme et al., 2013; Rosenblatt et al., 2016), but it was not. The relatively higher localized densities of preferred leopard prey (Table 3) remaining within our $228 \mathrm{~km}^{2}$ camera-trap area, compared to the rest of the Park, could explain the relatively high observed leopard density. This explanation is supported by the observation that we obtained more leopard detections at sites with higher localized densities of preferred prey (Fig. 2). These results also suggest that leopards may maintain higher densities where preferred prey remains abundant at small spatial scales within larger areas with lower prey density overall, such as Kafue. Leopards may kill smaller prey in other parts of the ecosystem, including the common duiker Sylvicapra grimmia, which remain relatively abundant throughout Kafue (Schuette et al., 2018; Vinks et al., 2020). However, dependency on such small prey is also expected to reduce population density (Henschel et al., 2011). Although the Greater Kafue Ecosystem as a whole is affected by prey depletion, pockets of higher relative prey abundance could affect large carnivore dynamics across the Greater Kafue Ecosystem, and 
TABLE 3 Densities of primary leopard prey in north-central Kafue National Park, and the proportion of the Kafue leopard diet comprised of each species, from Vinks et al. (2020) and Creel et al. (2018).

\begin{tabular}{|c|c|c|c|}
\hline Preferred prey species & $\begin{array}{l}\text { Mean individual density } \\
(95 \% \mathrm{CI}) \text {, per } \mathrm{km}^{2}\end{array}$ & $\begin{array}{l}\text { Mean herd density } \\
(95 \% \mathrm{CI}) \text {, per } \mathrm{km}^{2}\end{array}$ & $\begin{array}{l}\text { Proportion } \\
\text { of leopard diet }\end{array}$ \\
\hline Puku Kobus vardonii & $11.54(10.27-12.82)$ & $1.31(1.20-1.42)$ & 0.34 \\
\hline Impala Aepyceros melampus & $6.25(5.99-6.51)$ & $0.74(0.72-0.77)$ & 0.20 \\
\hline Warthog Phacochoerus africanus & $2.51(2.36-2.67)$ & $0.66(0.63-0.70)$ & 0.26 \\
\hline
\end{tabular}

appear to favour leopards in small areas that maintain relatively higher densities of their favoured prey (Fig. 2). Nonetheless, average leopard density across the entire Greater Kafue Ecosystem would still be expected to reflect low preferred prey abundance as a whole (Stander et al., 1997). A direct examination of these issues near the Park border and within the Game Management Areas would be of value.

Lions can limit the distribution and abundance of leopards (Stander et al., 1997; Balme et al., 2013), although recent findings suggest that interference competition with lions may be weaker than previously thought, particularly in secured protected areas with intact prey populations (Rosenblatt et al., 2016; Balme et al., 2017; Miller et al., 2018). The effects of intraguild competition might be stronger in prey-depleted ecosystems, particularly when large-bodied prey densities are disproportionally reduced (Balme et al., 2017; Creel et al., 2018). The diets of leopards and lions overlap extensively within our study area (Creel et al., 2018) because the larger-bodied prey preferred by lions have become rare (Vinks et al., 2020). This niche compression reduces the scope for dietary niche partitioning, and thus could strengthen the limiting effect of competition on subordinate competitors (Creel et al., 2018). However, we did not find evidence for this effect in Kafue. The distribution of leopard detections across space paralleled the core utilization distribution ( $60 \%$ isopleth of a kernel utilization distribution) for two resident lion prides in our study area (Fig. 3), suggesting that leopards did not avoid areas heavily used by lions throughout the dry season. However, lion density in Kafue is low (3.43 individuals per $100 \mathrm{~km}^{2}, 95 \%$ CI $2.79-4.23$ ) and pride size is small, with an average of 2.89 adult females per pride (Vinks et al., 2021). Accordingly, the ratio of leopards to lions per $100 \mathrm{~km}^{2}$ in this part of Kafue is 2.3:1 (HMMDM) and 0.97:1 (MMDM), compared to 0.82:1 (HMMDM) and 0.47:1 (MMDM) in a part of Zambia's South Luangwa National Park with favourable ecological conditions, where leopard and lion densities are both high (Rosenblatt et al., 2014, 2016). Such a substantial reduction in lion density could partially offset the anticipated effects of low prey densities on leopards in this part of the Park and could help explain a lack of evidence for intraguild competition.

Survival rates in our core study area were similar to estimates from another Zambian leopard population with better protection (Rosenblatt et al., 2016) and thus do not appear to be reduced by low prey density. Prior research with lions in this system also found that survival for resident individuals was high, but that lion density and cub recruitment were both low (Vinks et al., 2021). Thus measurements of adult survival may not be a good tool to evaluate the effects of prey depletion on large carnivore populations.

Our results have several important limitations. We were unable to monitor leopard recruitment effectively, and recruitment could be affected by low prey density (Balme et al., 2013). Our survival estimates were not partitioned across age classes (because we could not reliably age leopards using camera-trap photographs), which could have obscured variation in survival among age-sex classes. We note that survival rates for leopards outside our core study area, where human pressures are stronger (Watson et al., 2014; Overton et al., 2017), could be lower given lower overall leopard survival in human dominated landscapes (Swanepoel et al., 2015a,b). Wire-snare poaching could also be a source of mortality for leopards (Becker et al., 2013; Rosenblatt et al., 2014; Schuette et al., 2018), although we did not detect any snared leopards on our study site during the course of the study and snared leopards are rarely detected in Kafue, in contrast to snared wild dogs, spotted hyenas, and lions (Zambian Carnivore Programme, unpubl. data). Limited observations of snared leopards could be due in part to individuals succumbing to snares without ever breaking loose (Loveridge et al., 2020), as well as their cryptic nature.

Another limitation of our study was the inability to estimate abundance in multiple years, because of insufficient recapture rates. As a consequence, we were unable to evaluate potential annual trends in abundance, limiting our inferences about density to a single year. With that caveat, we did not observe substantial fluctuations in the number of leopards detected throughout the course of the study, and known individuals were consistently detected across multiple years (Table 1). Sample sizes were small, which may lead to unreliable abundance estimates (White et al., 1982), although precision was comparable to other published studies (Henschel et al., 2011; Stein et al., 2011; Maputla et al., 2013; Swanepoel et al., 2015a,b). Nonetheless, given that estimates of population size for leopards in miombo woodland are limited (Balme et al., 2007; Rosenblatt et al., 2016), especially where prey densities are disproportionately reduced, our density estimates are of high value from a conservation and management perspective. 
Although legal trophy hunting of adult male leopards occurred in Game Management Areas adjacent to the Park, except during a moratorium from January 2013 to April 2015 (Rosenblatt et al., 2016), trophy hunting was not a known direct cause of leopard mortality in this study. However, the effects of trophy hunting on leopard population dynamics (Balme et al., 2009a,b, 2010; Packer et al., 2011) are an important consideration closer to the edge of the Park and within the Game Management Areas. We recommend that legal harvest quotas reflect lower leopard densities expected in Game Management Areas (Rosenblatt et al., 2016) and account for the compounding effects of growing human pressures in the Game Management Areas on both leopards and their prey (Watson et al., 2014; Rosenblatt et al., 2016, 2019; Overton et al., 2017).

Overall, we observed moderate leopard density, good survival rates for both males and females, and consistent detections of individuals between years, strongly suggesting that the leopard population was relatively stable within our core study area. Research providing reliable and precise estimates of critical population parameters must continue throughout the Greater Kafue Ecosystem, to evaluate the effectiveness of management decisions and to allow a comparison of our findings with data from less-protected portions of the ecosystem. More broadly, similar research to describe the distribution and dynamics of intact carnivore guilds in response to prey depletion is essential across sub-Saharan Africa.

Acknowledgements We thank the Zambia Department of National Parks and Wildlife for permission to conduct this research, and for collaborative efforts to help monitor, manage and conserve these herbivore and carnivore populations. This research was supported by the National Science Foundation (IOS1145749), National Geographic Society Big Cats Initiative, Gemfields Inc., WWF Netherlands and Zambia, The Bennink Foundation, The Rufford Foundation, Wilderness Wildlife Trust, Painted Dog Conservation, Panthera, Ntengu Safaris, Elephant Charge, and IUCN Save Our Species/EU. Our findings and conclusions do not necessarily represent the views of the U.S. Fish \& Wildlife Service. This publication was produced with the financial support of the EU through IUCN Save Our Species, and is the sole responsibility of the Zambian Carnivore Programme and does not necessarily reflect the views of IUCN or the EU.

Author contributions Analysis, writing: MAV, SC; study design: SC, ER; field work: MAV, ER, CS, BG, KB; funding acquisition: MSB, ER, SC; project administration: MSB, CC, CS; revision, editing: MAV, SC, ER, PS, MSB, CS, BG, KB, CC, CS.

\section{Conflicts of interest None.}

Ethical standards This research abided by the Oryx guidelines on ethical standards.

\section{References}

Athreya, V., Odden, M., Linnell, J.D.C. \& Karanth, K.U. (2011) Translocation as a tool for mitigating conflict with leopards in human-dominated landscapes of India. Conservation Biology, $25,133-141$.
Balme, G.A., Batchelor, A., De Woronin Britz, N., Seymour, G., Grover, M., Hes, L. et al. (2013) Reproductive success of female leopards Panthera pardus: the importance of top-down processes. Mammal Review, 43, 221-237.

Balme, G.A., Hunter, L. \& Braczkowski, A.R. (2012) Applicability of age-based hunting regulations for African leopards. PLOS ONE, 7, e35209.

Balme, G.A., Hunter, L. \& Slotow, R. (2007) Feeding habitat selection by hunting leopards Panthera pardus in a woodland savanna: prey catchability versus abundance. Animal Behaviour, 74, 589-598.

Balme, G.A., Hunter, L.T.B. \& Slotow, R. (2009a) Evaluating methods for counting cryptic carnivores. Journal of Wildlife Management, 73, 433-441.

Balme, G.A., Lindey, P.A., Swanepoel, L.H. \& Hunter, L.T.B. (2014) Failure of research to address the rangewide conservation needs of large carnivores: leopards in South Africa as a case study. Conservation Letters, 7, 3-11.

Balme, G.A., Pitman, R.T., Robinson, H.S., Miller, J.R.B., Funston, P.J. \& Hunter, L.T.B. (2017) Leopard distribution and abundance is unaffected by interference competition with lions. Behavioral Ecology, 28, 1348-1358.

Balme, G.A., Rogan, M., Thomas, L., Pitman, R., Mann, G., Whittington-Jones, G. et al. (2019) Big cats at large: density, structure, and spatio-temporal patterns of a leopard population free of anthropogenic mortality. Population Ecology, 61, 256-267.

Balme, G.A., Slotow, R. \& Hunter, L.T.B. (2009b) Impact of conservation interventions on the dynamics and persistence of a persecuted leopard (Panthera pardus) population. Biological Conservation, 142, 2681-269o.

Balme, G.A., Slotow, R. \& Hunter, L.T.B. (2010) Edge effects and the impact of non-protected areas in carnivore conservation: Leopards in the Phinda-Mkhuze Complex, South Africa. Animal Conservation, 13, 315-323.

Becker, M., McRobb, R., Watson, F., Droge, E., Kanyembo, B., Murdoch, J. \& KaKumbi, C. (2013) Evaluating wire-snare poaching trends and the impacts of by-catch on elephants and large carnivores. Biological Conservation, 158, 26-36.

Bolger, D.T., Newmark, W.D., Morrison, T.A. \& Doak, D.F. (2008) The need for integrative approaches to understand and conserve migratory ungulates. Ecology Letters, 11, 63-77.

Creel, S. \& Creel, N.M. (2002) The African Wild Dog: Behavior, Ecology, and Conservation. Princeton University Press, Princeton, USA.

Creel, S., Matandiko, W., Schuette, P., Rosenblatt, E., Sanguinetti, C., Banda, K. et al. (2018) Changes in African large carnivore diets over the past half-century reveal the loss of large prey. Journal of Applied Ecology, 55, 2908-2916.

Devens, C.H., Hayward, M.W., Tshabalala, T., Dickman, A., McManus, J.S., Smuts, B. \& Somers, M.J. (2019) Estimating leopard density across the highly modified human-dominated landscape of the Western Cape, South Africa. Oryx, 55, 34-45.

Du Preez, B.D., Loveridge, A.J. \& Macdonald, D.W. (2014) To bait or not to bait: a comparison of camera-trapping methods for estimating leopard Panthera pardus density. Biological Conservation, 176, 153-161.

Durant, S.M., Bashir, S., Maddox, T. \& Laurenson, M.K. (2007) Relating long-term studies to conservation practice: the case of the serengeti cheetah project. Conservation Biology, 21, 602-611.

EBERHARDT, L.L. (2002) A paradigm for population analysis of long-lived vertebrates. Ecology, 83, 2841-2854.

Efford, M.G., Dawson, D.K. \& Robins, C.S. (2004) DENSITY: software for analysing capture-recapture data from passive detector arrays. Animal Biodiversity and Conservation, 27, 217-228. 
FA, J.E. \& Brown, D. (2009) Impacts of hunting on mammals in African tropical moist forests: a review and synthesis. Mammal Review, 39, 231-264.

Fa, J.E., Yuste, J.E.G. \& Castelo, R. (200o) Bushmeat Markets on Bioko Island as a measure of hunting pressure. Conservation Biology, 14, 1602-1613.

Goldberg, J.F., Tempa, T., Norbu, N., Hebblewhite, M., Mills, L.S., WANGCHUK, T.R. \& LuKacs, P. (2015) Examining temporal sample scale and model choice with spatial capture-recapture models in the common leopard Panthera pardus. PLOS ONE, 10, e0140757.

GraY, T.N.E. \& PrUM, S. (2012) Leopard density in post-conflict landscape, Cambodia: evidence from spatially explicit capturerecapture. Journal of Wildlife Management, 76, 163-169.

Hayward, M.W. \& Kerley, G.I.H. (2005) Prey preferences of the lion (Panthera leo). Journal of Zoology, 267, 309-322.

Henschel, P., Hunter, L.T.B., Coad, L., Abernethy, K.A. \& Mühlenberg, M. (2011) Leopard prey choice in the Congo Basin rainforest suggests exploitative competition with human bushmeat hunters. Journal of Zoology, 285, 11-20.

Hofer, H. \& EAst, M.L. (1995) Population dynamics, population size and the commuting system of spotted hyaenas in the Serengeti. In Serengeti II: Dynamics, Management and Conservation of an Ecosystem (eds A.R.E. Sinclair \& P. Arcese), pp. 332-363. University of Chicago Press, Chicago, USA.

HugGins, R.M. (1989) On the statistical analysis of capture experiments. Biometrika, 76, 133-140.

Jacobson, A.P., Gerngross, P., Lemeris, J.R., Schoonover, R.F., Anco, C., Breitenmoser-Würsten, C. et al. (2016) Leopard (Panthera pardus) status, distribution, and the research efforts across its range. PeerJ, 2016, 1-28.

KaRANTH, K.U. (1995) Estimating tiger Panthera tigris populations from camera-trap data using capture-recapture models. Biological Conservation, 71, 333-338.

Karanth, K.U. \& Nichols, J.D. (1998) Estimation of tiger densities in India using photographic captures and recaptures. Ecology, 79, 2852.

Kendall, W.L., Pollock, K.H. \& Brownie, C. (1995) A likelihood-based approach to capture-recapture estimation of demographic parameters under the robust design. Biometrics, 51, 293-308.

LAAKE, J.L. (2013) RMark: An R interface for analysis of capture-recapture data with MARK. National Marine Fisheries Service, Seattle, USA.

LAURENSON, M.K. (1995) Implication of high offspring mortality for cheetah population dynamics. In Serengeti II: Dynamics, Management and Conservation of an Ecosystem (eds A.R.E. Sinclair \& P. Arcese), pp. 385-399. University of Chicago Press, Chicago, USA.

Loveridge, A.J., Sousa, L.L., Seymour-Smith, J., Hunt, J., Coals, P., Donnell, H.O. et al. (2020) Evaluating the spatial intensity and demographic impacts of wire-snare bush-meat poaching on large carnivores. Biological Conservation, 244, 108504.

Maputla, N.W., Chimimba, C.T. \& Ferreira, S.M. (2013) Calibrating a camera trap-based biased mark-recapture sampling design to survey the leopard population in the N'wanetsi concession, Kruger National Park, South Africa. African Journal of Ecology, 51, 422-430.

Marker, L.L. \& Dickman, A.J. (2005) Factors affecting leopard (Panthera pardus) spatial ecology, with particular reference to Namibian farmlands. African Journal of Wildlife Research, $35,105-115$.

Midlane, N., O’Riain, M.J., Balme, G.A., Robinson, H.S. \& Hunter, L.T.B. (2014) On tracks: a spoor-based occupancy survey of lion Panthera leo distribution in Kafue National Park, Zambia. Biological Conservation, 172, 101-108.
Miller, J.R.B., Pitman, R.T., Mann, G.K.H., Fuller, A.K. \& Balme, G.A. (2018) Lions and leopards coexist without spatial, temporal or demographic effects of interspecific competition. Journal of Animal Ecology, 87, 1709-1726.

Miththapala, S., Seidensticker, J., Phillips, L.G., Fernando, S.B.U. \& SMALLWOOD, J.A. (1989) Identification of individual leopards. Journal of Zoology, 218, 527-536.

Mweetwa, T., Christianson, D., Becker, M., Creel, S., Rosenblatt, E., Merkle, J. et al. (2018) Quantifying lion (Panthera leo) demographic response following a three-year moratorium on trophy hunting. PLOS ONE, 13, eo197030.

Naude, V.N., Balme, G.A., Riain, J.O., Hunter, L.T.B., Fattebert, J., Dickerson, T. \& Bishop, J.M. (2020) Unsustainable anthropogenic mortality disrupts natal dispersal and promotes inbreeding in leopards. Ecology and Evolution, 10, 3605-3619.

Nijman, V., Morcatty, T., Smith, J.H., Atoussi, S., Shepherd, C.R., Siriwat, P. et al. (2019) Illegal wildlife trade-surveying open animal markets and online platforms to understand the poaching of wild cats. Biodiversity, 20, 58-61.

Odden, M., Athreya, V., Rattan, S. \& Linnell, J.D.C. (2014) Adaptable neighbours: movement patterns of GPS-collared leopards in human dominated landscapes in India. PLOS ONE, 9, $\mathrm{e} 112044$

Otis, D.L., Burnham, K.P., White, G.C. \& Anderson, D.R. (1978) Statistical inference from capture data on closed animal populations. Wildlife Monographs, 62, 3-135.

Overton, J., Davies, S., Nguluka, L., Chibeya, D., Sompa, B., Simukond A, C. \& Lindsey, P.A. (2017) The Illegal Bushmeat Trade in the Greater Kafue Ecosystem, Zambia, Drivers, Impacts and Potential Solutions. FAO/Department of National Parks and Wildlife/Panthera/Game Rangers International, Zambia.

Packer, C., Brink, H., Kissui, B.M., Maliti, H., Kushnir, H. \& Caro, T. (2011) Effects of trophy hunting on lion and leopard populations in Tanzania. Conservation Biology, 25, 142-153.

Paterson, J.T., Proffitt, K., Jimenez, B., Rotella, J. \& Garrott, R. (2019) Simulation-based validation of spatial capture-recapture models: a case study using mountain lions. PLOS ONE, 14, eo215458.

Pledger, S., Pollock, K.H. \& Norris, J.L. (2010) Open capture-recapture models with heterogeneity: II. Jolly-Seber model. Biometrics, 66, 883-89o.

Pollock, K.H. (1982) A capture-recapture sampling design robust to unequal catchability. Journal of Wildlife Management, 46, 757-760.

Purchase, G., Mateke, C. \& Purchase, D. (2007) A Review of the Status and Distribution of Carnivores, and Levels of HumanCarnivore Conflict, in the Protected Areas and Surrounds of the Zambezi Basin. Unpublished report, The Zambezi Society, Bulawayo, Zimbabwe.

RAY, R.-R. (2011) Ecology and population status and the impact of trophy hunting of the leopard Panthera pardus (Linnaeus, 1758) in the Luambe National Park and surrounding Game Management Areas in Zambia. PhD thesis, Rheinische FriedrichWilhelms-Universität, Bonn, Germany.

Ripple, W.J., Estes, J.A., Beschta, R.L., Wilmers, C.C., Ritchie, E.G., Hebilewhite, M. et al. (2014) Status and ecological effects of the world's largest carnivores. Science, 343, 1241484.

Ripple, W.J., Newsome, T.M., Wolf, C., Dirzo, R., Everatt, K.T., Galetti, M. et al. (2015) Collapse of the world's largest herbivores. Science Advances, 1, e1400103.

Rosenblatt, E., Becker, M.S., Creel, S., Droge, E., Mweetwa, T., Schuette, P.A. et al. (2014) Detecting declines of apex carnivores and evaluating their causes: an example with Zambian lions. Biological Conservation, 180, 176-186.

Rosenblatt, E., Creel, S., Becker, M.S., Merkle, J., Mwape, H., Schuette, P. \& Simpamba, T. (2016) Effects of a protection 
gradient on carnivore density and survival: an example with leopards in the Luangwa valley, Zambia. Ecology and Evolution, 6, 3772-3785.

Rosenblatt, E., Creel, S., Schuette, P., Becker, M.S., Christianson, D., Dröge, E. et al. (2019) Do protection gradients explain patterns in herbivore densities? An example with ungulates in Zambia's Luangwa valley. PLOS ONE, 14, eo224438.

Schaller, G.B. (1972) The Serengeti Lion. A Study of Predator-Prey Relations. University of Chicago Press, Chicago, USA.

Schuette, P., Namukonde, N., Becker, M.S., Watson, F.G.R. Creel, S., Chifunte, C. et al. (2018) Boots on the ground: in defense of low-tech, inexpensive, and robust survey methods for Africa's under-funded protected areas. Biodiversity and Conservation, 27, 2173-2191.

Silver, S.C., Ostro, L.E.T., Marsh, L.K., Maffei, L., Noss, A.J., Kelly, M.J. et al. (2004) The use of camera traps for estimating jaguar Panthera onca abundance and density using capture/ recapture analysis. Oryx, 38, 148-154.

Stander, P.E., Haden, P.J., Kaqece, II \& Ghau, II (1997) The ecology of asociality in Namibian leopards. Journal of Zoology, 242, 343-364.

Stein, A.B., Athreya, V., Gerngross, P., Balme, G., Henschel, P., Karanth, U. et al. (2020) Panthera pardus (amended version of 2019 assessment). In The IUCN Red List of Threatened Species 2020. dx.doi.org/10.2305/IUCN.UK.2020-1.RLTS.T15954A163991139.en [accessed 23 March 2021].

Stein, A.B., Fuller, T.K., Destefano, S. \& Marker, L.L. (2011) Leopard population and home range estimates in north-central Namibia. African Journal of Ecology, 49, 383-387.

STICKEL, L.F. (1954) A comparison of certain methods of measuring ranges of small mammals. Journal of Mammalogy, 35, 1-15.

Swanepoel, L.H., Lindsey, P., Somers, M.J., van Hoven, W. \& Dalerum, F. (2013) Extent and fragmentation of suitable leopard habitat in South Africa. Animal Conservation, 16, 41-50.

Swanepoel, L.H., Somers, M.J. \& Dalerum, F. (2015a) Density of leopards Panthera pardus on protected and non-protected land in the Waterberg Biosphere, South Africa. Wildlife Biology, 21, 263-268.

Swanepoel, L.H., Somers, M.J., van Hoven, W., Schiess-Meier, M., Owen, C., Snyman, A. et al. (2015b) Survival rates and causes of mortality of leopards Panthera pardus in southern Africa. Oryx, 49, 595-603.
Swanson, A., Caro, T., Davies-Mostert, H., Mills, M.G.L., Macdonald, W., Borner, M. et al. (2014) Cheetahs and wild dogs show contrasting patterns of suppression by lions. Journal of Animal Ecology, 83, 1418-1427.

Tobler, M.W. \& Powell, G.V.N. (2013) Estimating jaguar densities with camera traps: problems with current designs and recommendations for future studies. Biological Conservation, $159,109-118$.

Troumborst, A., Loveridge, A.J. \& Macdonald, D.W. (2019) Spotty data: managing international leopard (Panthera pardus) trophy hunting quotas amidst uncertainty. Journal of Environmental Law, 32, 253-278.

Van Orsdol, K.G., Hanby, J.P. \& Bygott, J.D. (1985) Ecological correlates of lion social organization (Panthera leo). Journal of Zoology, 206, 97-112.

Vinks, M.A., Creel, S., Schuette, P., Becker, M.S., Rosenblatt, E., SAnguinetti, C. et al. (2021) Response of lion demography and dynamics to the loss of preferred larger prey. Ecological Applications, 31, eo2298.

Vinks, M.A., Creel, S., Schuette, P., Rosenblatt, E., Matandiko, W., SAnguinetti, C. et al. (2020) Testing the effects of anthropogenic pressures on a diverse African herbivore community. Ecosphere, 11, e03067.

Watson, F.G.R., Becker, M.S., Milanzi, J. \& Nyirenda, M. (2014) Human encroachment into protected area networks in Zambia: implications for large carnivore conservation. Regional Environmental Change, 15, 415-429.

Western, D., Russell, S. \& Cuthil, I. (2009) The status of wildlife in protected areas compared to non-protected areas of Kenya. PLOS ONE, 4, e6140.

White, G.C., Anderson, D.R., Burnham, K.P. \& Otis, D.L. (1982) Capture-Recapture and Removal Methods for Sampling Closed Populations. Los Alamos National Laboratory, Los Alamos, USA.

White, G.C. \& Burnam, K.P. (1999) Program MARK: Survival estimation from populations of marked animals. Bird Study, 46(sup1), S120-S139.

Wilkie, D.S. \& Carpenter, J. (1999) Bushmeat hunting in Congo Basin: an assessment of impacts and options for mitigation. Biodiversity and Conservation, 8, 927-955.

Wilson, K.R. \& Anderson, D.R. (1985) Evaluation of two density estimators of small mammal population size. Journal of Mammalogy, 66, 13-21. 